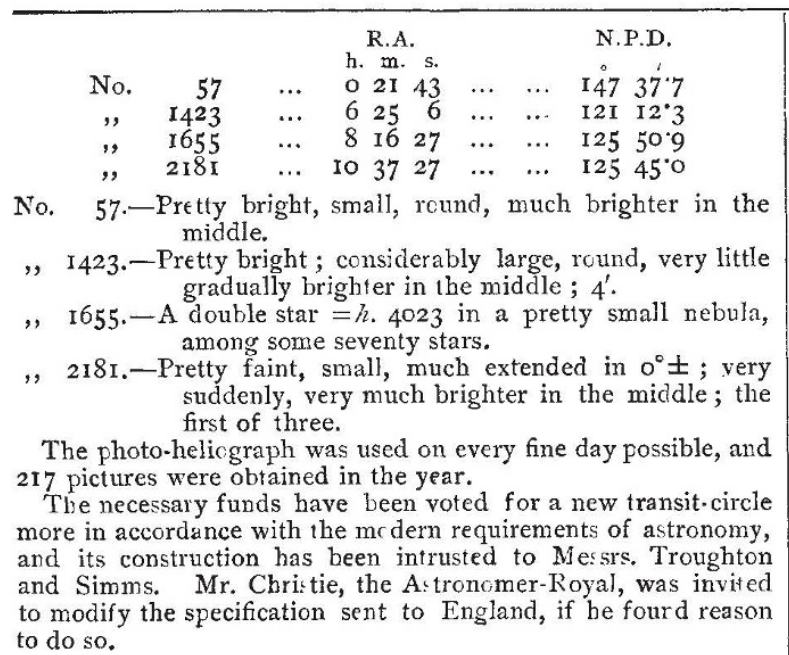

The Supposed Variable $\mu$ DORAdÛs-A SPURIous Star. -Dr. B. A. Gculd has made a very unexpected discovery, from which it appears that $\mu$ Doradûs of our catalogues, long supposed to be a variable star, was never observed by Lacaille in the position he assigns it in the Catalc gue of the Colum Australe Stelliferum, and further, that by similar error, five other stars observed by Lacaille on the same day, which are found in the reduced catalogue published ty the British Association, have no existence in the positions given. The case is a curious one, and as the Colum Australe of Lacaille is now a scarce work, we may be excused for transcribing the observations in question as they stand. They were made in Zone XI., I75I, December I6, in parte inferiore of Lacaille's rhomboid ; the numerals are our own :-

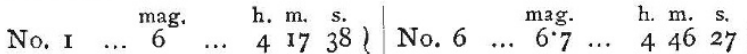

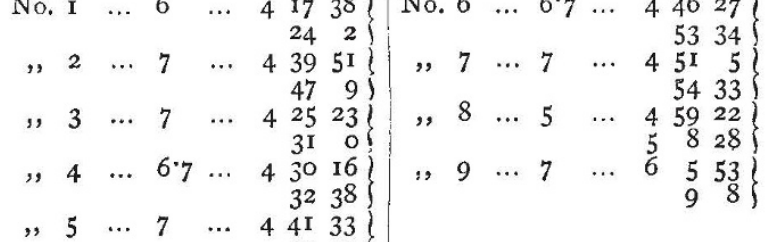

$$
\begin{aligned}
& \left.\begin{array}{rlllrrr}
5 & \cdots & 7 & \cdots & 4 & 41 & 33 \\
43 & 4 \mathrm{I}
\end{array}\right\}
\end{aligned}
$$

Lacaille appears to have entered correctly the times of beginning and ending of describing the chord of his rhomboid for Nos. I and 2 , but instead of $4 \mathrm{~h} .25 \mathrm{~m} .23 \mathrm{~s}$. for the third star, the time was really $5 \mathrm{~h}, 25 \mathrm{~m}, 23 \mathrm{~s}$., and this error of $\mathrm{Ih}$, runs on up to No. 8 inclusive; No. 9 is correct. This will be readily seen by inspecting the above times. The star entered in the Catalogue as $\mu$ Doradûs is No. 8 , called $5 \mathrm{~m}$. in the observations but $6 \mathrm{~m}$. in the Catalogne, which gives its place for $175^{\circ} \circ$, R. A. $76^{\circ}$ I I $^{\prime} I^{\prime \prime}$, Decl. $-62^{\circ} 7^{\prime} 4^{\prime \prime}$. The place given by the B.A. reductions is R.A. 5h. $4 \mathrm{~m}, 44^{\circ} 3$ s., N.P.D. $152^{\circ} 6^{\prime} 57^{\prime \prime}$, which is correctly deduced from the transits as printed. With the correction of $+\mathrm{Ih}$. to the times, the position for $175^{\circ}$ becomes R.A. 6h. $4 \mathrm{~m}, 44^{\circ} 2$ s., N.P.D. I $52^{\circ} 6^{\prime} 49^{\prime \prime}$, and the star " $\mu$ Doradûs" is seen to be identical with Brisbane $1172=$ B.A.C. $2000=$ Stone 2836 , in Pictor. The other spurious stars introduced in the Catalogue by the error which Dr. Gould has brought to light are Nos. 1542, 1554, 1633, 1680, and 1706. The following identifications of the stars really observed may be useful :-

$$
\begin{aligned}
& \text { Spurious stars of the reduced Stars really observed by } \\
& \text { Catalogue. } \\
& \text { No. }{ }_{1542} \text { Reticulum } 7 \mathrm{~m} .=\text { Stone } 2497 \text {, Dorado } 7.6 \mathrm{~m} \text {. }
\end{aligned}
$$

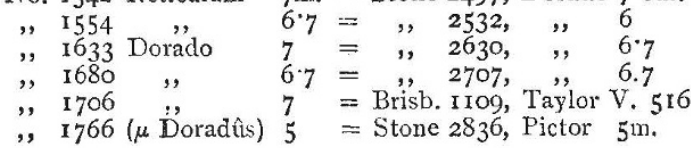

Brisbane observed a star close upon Lacaille's erroneous position of his $\mu$ Doradûs, and according to his general custom gave it Lacaille's magnitude. Moesta (Astron. Nach., No. 1545) stated that he had observed this star at Santiago de Chile from February, 1860, to January, I865, and had found it $8 \frac{1}{2}$ or 9 of
Argelander's scale; he therefore conijdered it to be variable, and thought the period of variatic $n$ would preve to be of long duration.

THE COMET OF I812.- MM. Schulhof and Boss ert's sweeping ephemerides for this comet are continued in No. 2489 of the Astronomische Nachrichten.

\section{INSECTS VISITING FLOWERS}

THE interest arising out of the writings of Darwin, Lubbock, and Hermann Muiller relative to the part played by insects in their oft-recurring visits to flowers has of late years attracted much attention. The subject, in fact, has created a taste for observation, and an incentive has been given to watch the frequency of visits of various species to certain flowers, and especially to the insects' choice of colours of flower. While the mere registering of visits may se $\mathrm{m}$ a comparatively simple one, the reason why insects should show a preference to alight upon flowers of a certain colour, or choose certain species of plants, is a much more complicated problem than at first sight it would appear. Sir John Lubbcck has shown by experiment that blue is the bees' favourite colour; $H$. Muiller avers that in the Alps bees are attracted to the yellow rather than the white flowers. However this may be, certain it is that a much larger number of c bservations are yet needed before a positive law can be deduced. Two papers read at the Jast meeting of the Linnean Society (March I) : one by Mr. Alf. W. Bennett, "On the Constancy of Insects in their Visits to Flowers," and the other by Mr. R. M. Christy, "On the Methodic Habits of Insects when Visiting Flowers"- -point out that a strict watch and ward is being kept on the movements of the busy bee and its kindred. $\mathrm{Mr}$. Bennett states that butterflies show but little constancy in their visits, citing only a few instances to the contrary; but according to him, to some extent they seem to have a choice of colour. The Diptera exhibit greater constancy, though by no means absolute. The Apidæ, especially the hive-bee, manifest still greater constancy. From these data he infers that the ratio of increase is in proportion to the part performed by the insects in their carrying pollen from flower to flower. As respects preference for particular colours, in a series of observations Mr. Bennett has noted among the Lepidoptera that 70 visits were made to red or pink flowers, 5 to blue, 15 to yellow, and 5 to white; the Diptera paid 9 visits to red or pink, 8 to yellow, and 20 to w hite; Hymenoptera alighted 303 times on red and pink flowers, I 26 on blue, II on yellow, and I 7 on white flowers. Mr. Christy records in detail the movements of 76 insects, chiefly bees, when engaged in visiting 2400 flowers. He tabulates the same, and concludes therefrom that insects, notably the bees, decidedly and with intent confine their successive visits to the same species of flower. According to him, also, butter flies generally wander aimlessly in their flight : yet some species, including the Fritillaries, are fairly methodical in their habit. He believes that it is not by colour alone that insects are guided from one flower to another of the same species, and he suggests that the sense of smell may be brought into play. Bees, he avers, have but poor sight for long distances, but see well at short distances. Of 55 humble-bees watched, 26 visited blue flowers: of these 12 were methodic in their visits, 9 only irregularly so, and 5 not at all ; I3 visited white flowers, whereof 5 were methodic and 8 the reverse; II visited yellow flowers, of which 5 were methodic and 6 not; 28 visited red flowers, 7 appearing methodic, ? nearly so, while 12 were the contrary.

\section{UNIVERSITY AND EDUCATIONAI INTELLIGENCE}

CAMBRIDGE.-In the last local examination 17 per cent. of those Juniors who sent up papers in Trigonometry obtained no marks, although some questions were of the very simplest nature. Among the Seniors Hydrostatics produced unsatisfactory answers. Many candidates had no ideas worth the 3 ame about pressure at a point, density, specific gravity, and weight. This is due partly to corresponding imperfections in some current text-books, and partly to the habit of teaching Hydrostatics apart from general physics or practical applications. The answers in Statics were the least satisfactory; yet according to the examiner there are few sub;ects in which gocd teaching tells more yuickly than in elementary mechanics. Thus many who passed did very good papers. 